\title{
Ações educativas desenvolvidas no período perioperatório em um hospital universitário: percepção de pacientes cirúrgicos
}

Educational actions developed in the perioperative period in a university hospital: perception of surgical patients

Acciones educativas desarrolladas en el período perioperatorio en un hospital universitario: percepción de pacientes quirúrgicos

\section{Andressa Böck ${ }^{\mathrm{I}}$, Elisabeta Albertina Nietsche ${ }^{\mathrm{II}}$, Marlene Gomes Terra ${ }^{\mathrm{III}}$ Liege Gonçalves Cassenote ${ }^{\mathrm{IV}}$, Camila Fernandes Wild" ${ }^{\mathrm{V}}$ Cléton Salbego ${ }^{\mathrm{VI}}$}

Resumo: Objetivo: analisar a percepção de pacientes cirúrgicos de um hospital universitário acerca das ações educativas desenvolvidas no período perioperatório. Método: pesquisa qualitativa, descritiva e exploratória, realizada com oito pacientes de uma Unidade de Cirurgia Geral. Os depoimentos foram coletados por meio de entrevistas semiestruturadas no período de março a maio de 2016. A avaliação dos dados ocorreu por meio da análise de conteúdo temático. Resultados: emergiram três categorias: ações educativas desenvolvidas no período perioperatório na percepção dos pacientes; contribuições das ações educativas; e sentimentos manifestados pelos pacientes durante o período perioperatório. Conclusão: destaca-se a necessidade de repensar o método das ações educativas desenvolvidas pela equipe multiprofissional de saúde, bem como enriquecer o processo de comunicação enfermagem-paciente, a fim do reconhecimento do trabalho desenvolvido.

\footnotetext{
${ }^{\text {I }}$ Enfermeira. Mestre em Enfermagem pelo Programa de Pós-Graduação em Enfermagem da Universidade Federal de Santa Maria (UFSM). Santa Maria, Rio Grande do Sul, Brasil. E-mail: bockandressa@gmail.com. ORCID:0000-0002-9423-5155

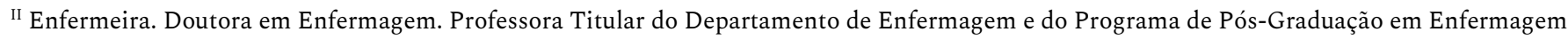
da Universidade Federal de Santa Maria (UFSM). Santa Maria, Rio Grande do Sul, Brasil. E-mail: eanietsche@gmail.com. ORCID:0000-00028006-2038

${ }^{\text {III }}$ Enfermeira. Doutora em Enfermagem. Professora do Programa de Pós-Graduação em Enfermagem da Universidade Federal de Santa Maria (UFSM). E-mail: martesm@hotmail.com.br. ORCID:0000-0001-9402-561X

IV Enfermeira. Mestre em Enfermagem. Enfermeira assistencial no Hospital Universitário de Santa Maria (HUSM). Santa Maria, Rio Grande do Sul, Brasil. E-mail: liege.gcassenote@hotmail.com. ORCID: 0000-0003-0833-4016

${ }^{v}$ Enfermeira. Mestre em Enfermagem pelo Programa de Pós-Graduação em Enfermagem da Universidade Federal de Santa Maria (UFSM). Santa Maria, Rio Grande do Sul, Brasil. E-mail: camilinhah_wild@hotmail.com. ORCID:0000-0003-0828-9147

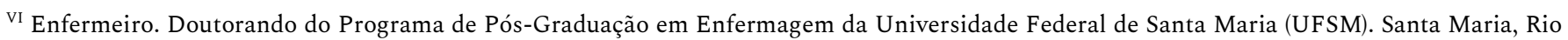
Grande do Sul, Brasil. E-mail: cletonsalbego@hotmail.com. ORCID:0000-0003-3734-9970
} 
Ações educativas desenvolvidas no período perioperatório em um hospital universitário... I 2

Descritores: Educação em saúde; Período perioperatório; Hospitais universitários

\begin{abstract}
Aim: to analyze the perception of surgical patients of a university hospital about the educational actions developed during the perioperative period. Method: qualitative, descriptive and exploratory research, performed with eight patients from a General Surgery Unit. The statements were collected through semistructured interviews from March to May of 2016. The data evaluation occurred from the analysis of thematic content. Results: three categories emerged: educational actions developed during the perioperative period in patients' perception; contributions of educational actions; and feelings showed by patients during the perioperative period. Conclusion: it is necessary to rethink the method of educational actions developed by the multiprofessional health team, as well as to enrich the nursing-patient communication process, in order to recognize the work developed.
\end{abstract}

Descriptors: Health education; Perioperative period; University Hospitals

Resumen: Objetivo: analizar la percepción de pacientes quirúrgicos de un hospital universitario sobre las acciones educativas desarrolladas en el período perioperatorio. Método: investigación cualitativa, descriptiva y exploratoria, realizada con ocho pacientes de una Unidad de Cirugía General. Los testimonios fueron recolectados por medio de entrevistas semiestructuradas, entre marzo y mayo de 2016. La evaluación de los datos ocurrió por medio del análisis de contenido temático. Resultados: surgieron tres categorías: acciones educativas desarrolladas en el período perioperatorio desde la percepción de los pacientes; contribuciones de las acciones educativas; y los sentimientos manifestados por los pacientes durante el período perioperatorio. Conclusión: se destaca la necesidad de repensar el método de las acciones educativas desarrolladas por el equipo multiprofesional de salud, así como enriquecer el proceso de comunicación enfermería-paciente, a fin del reconocimiento del trabajo desarrollado.

Descriptores: Educación en salud; Período perioperatorio; Hospitales universitarios.

\title{
Introdução
}

O procedimento cirúrgico é uma atividade realizada por uma equipe especializada em função da complexidade que esse envolve. A especificidade desse procedimento exige cuidados, que precisam ser desenvolvidos com orientações e intervenções terapêuticas, que transcendam aspectos técnicos e físicos, ou seja, que leve em consideração o ser humano como ser digno de atenção, respeito e escuta. ${ }^{1}$

Neste sentido, considera-se imprescindível o desenvolvimento de ações educativas direcionadas ao paciente e seu acompanhante, de modo a estimulá-los acerca da importância de assumirem comportamentos e atitudes de acordo com as necessidades de cuidado. Também, no período perioperatório, as equipes de saúde precisam desenvolver suas condutas junto ao paciente cirúrgico de modo a proporcionar segurança e tranquilidade. Para isso, recomenda-se a 
comunicação como estratégia para orientar e informar, visando o atendimento das particularidades de cada ser humano, o que conduzirá a um cuidado específico, de acordo às necessidades e expectativas do indivíduo a ser submetido a um procedimento cirúrgico..$^{2-3}$

O interesse para a realização desta investigação se deu devido a vivência prévia da pesquisadora dentro da unidade de cirurgia geral, buscando assim aprofundar conhecimentos acerca da temática. Portanto, denota-se a relevância deste estudo para a constante reflexão e agir da equipe multiprofissional de saúde, nas ações educativas perioperatórias e bem estar do paciente cirúrgico.

Frente ao contexto apresentado, esta pesquisa questiona: qual a percepção dos pacientes cirúrgicos de um hospital universitário, acerca das ações educativas desenvolvidas pela equipe multiprofissional de saúde? Este estudo possui como objetivo analisar a percepção de pacientes cirúrgicos de um hospital universitário acerca das ações educativas desenvolvidas no período perioperatório.

\section{Método}

Trata-se de uma pesquisa qualitativa, do tipo exploratória e descritiva. O estudo foi desenvolvido na Unidade de Cirurgia Geral de um Hospital Universitário do Estado do Rio Grande do Sul, (RS), Brasil. O cenário estudado contemplava 50 leitos e atendia nove especialidades cirúrgicas: cabeça e pescoço, geral, plástica, torácica, vascular, proctologia, traumatologia, gastrodigestiva e urologia.

Foram eleitos os seguintes critérios de inclusão: pacientes internados na Unidade de Cirurgia Geral do referido Hospital Universitário, que se encontravam no período pósoperatório (subentendo-se que já poderiam ter vivenciado as ações educativas pré e/ou pós operatórias) e, possuir idade igual ou superior a 18 anos. Salienta-se que apenas um paciente de cada especialidade foi considerado como participante. Logo, nos casos em que houve mais de 
um paciente apto a participar do estudo em cada especialidade, este foi excluído por já haver representação na investigação. É válido destacar que a seleção dos participantes foi intencional, após contato com a gestão do serviço de enfermagem cirúrgica para identificação dos pacientes internados.

Como critério de exclusão, foram considerados inaptos para a pesquisa os pacientes com capacidade de comunicação verbal comprometida. Durante o processo de coleta de dados, três pacientes não aceitaram participar sem especificar a razão e, dois desistiram durante a entrevista em decorrência do desconforto e algia pós-operatória. A amostra final desta pesquisa finalizou em oito participantes, tendo em vista que não houve no período da coleta dos dados, pacientes internados na especialidade de gastro digestivo que atendessem aos critérios de inclusão e exclusão.

A coleta de dados foi realizada pela discente de enfermagem autora da pesquisa no período de março a maio de 2016, por meio de entrevista semi estruturada e gravada em áudio para posterior transcrição e observação não participante. As observações foram realizadas com o auxílio de um roteiro, a fim de identificar os pacientes que foram orientados, qual/quais profissional de saúde realizou as orientações, bem como o modo com que foram realizadas. Os dados observados foram registrados em diário de campo. Após foram realizadas as entrevistas, e estas buscaram traçar o perfil sociodemográfico dos participantes, identificar como foram desenvolvidas as orientações, quais ações foram desenvolvidas, quem as realizou e os sentimentos vivenciados pelo paciente no período perioperatório. A pesquisadora já possuía experiência nestas técnicas de coleta de dados, a partir da participação em outras pesquisas. Ainda, foi realizado um teste piloto com a entrevista semiestruturada e realizadas algumas adequações. Assim, no momento do convite para participação que foi realizado pessoalmente, a pesquisadora apresentou os objetivos da pesquisa, razões para sua realização e interesses em relação a mesma. 
5 | Böck A, Nietsche EA, Terra MG, Cassenote LG, Wild CF, Salbego C

As entrevistas ocorreram de acordo com a disponibilidade dos pacientes e em locais de sua preferência, variando entre o leito e uma sala reservada e individualizadas para que favorecessem o sigilo e a privacidade. Nos momentos em que os participantes solicitaram que a entrevista fosse realizada no leito, foi utilizado um biombo para promover a privacidade. A duração das entrevistas variou entre 35 minutos e uma hora e 40 minutos. Os participantes foram identificados com a letra "P” correspondente a participante, sequenciada de um numeral (P1...P8).

Os dados foram analisados conforme Análise de Conteúdo. ${ }^{4} \mathrm{Na}$ etapa de pré-análise foi realizada a leitura flutuante das entrevistas transcritas, visando identificar os núcleos de sentido. Concomitantemente, se iniciou o processo de destaque (marcação) destes núcleos que respondiam ao objeto de estudo. $\mathrm{Na}$ etapa de exploração do material, foi realizada leitura aprofundada, procedendo-se a identificação e extração das unidades de registro e de contexto, para assim, iniciar o processo de agrupamento por semelhança, atendendo aos critérios de exaustividade, representatividade, homogeneidade, pertinência e exclusividade. Na etapa de tratamento e interpretação, se realizou o agrupamento das unidades, o que fez emergir duas categorias analíticas: ações educativas desenvolvidas no período perioperatório na percepção dos pacientes; contribuições das ações educativas no perioperatório; e sentimentos manifestados pelos pacientes durante o período perioperatório. Por fim, na etapa do tratamento dos dados obtidos e interpretação, foram realizadas as inferências e as interpretações, norteando-se nos significados e conhecimentos das mensagens emitidas pelos participantes, correlacionando-as e contrastando-as com os referenciais específicos relacionados a educação em saúde e de abordagem ao paciente cirúrgico.

Os princípios éticos foram respeitados, conforme a Resolução 466/12. O estudo foi aprovado pelo Comitê de Ética em Pesquisa da Universidade Federal de Santa Maria no dia 13 de janeiro de 2016, sob o parecer número 52275916.0.0000.5346. 


\section{Resultados}

Fizeram parte desta pesquisa oito $(100,0 \%)$ pacientes cirúrgicos, sendo que $62,5 \%$ eram homens e 37,5\% mulheres. Quanto à idade dos pacientes, $62,5 \%$ corresponderam idade acima de 50 anos e, 37,5\% inferior aos 25 anos. Em relação a escolaridade, $62,5 \%$ dos pacientes no pósoperatório possuíam Ensino Fundamental Incompleto, 12,5\% Ensino Médio Incompleto, 12,5\% Ensino Médio Completo e, 12,5\% Ensino Superior Incompleto. Quanto a profissão dos participantes, $50 \%$ eram aposentados, $12,5 \%$ atendente de caixa, $12,5 \%$ cuidador de pessoas idosas, $12,5 \%$ estudante e $12,5 \%$ pedreiro. Quanto ao intervalo de tempo entre internação e a realização do procedimento cirúrgico, 37,5\% dos entrevistados realizaram a cirurgia em até 24 horas, $25 \% 24$ horas após a internação, 25\% 48 horas após a internação e 12,5\% mais de 72 horas após a internação.

Os resultados foram organizados em três categorias. Na categoria intitulada "Ações educativas desenvolvidas no período perioperatório na percepção dos pacientes”, pode ser compreendida a maneira como os pacientes identificam estas ações, o local onde as mesmas foram realizadas e as demandas para tais ações. Em sequência, a categoria denominada "Contribuições das ações educativas no perioperatório", traz o efeito positivo em relação às ações realizadas pelos profissionais, evidenciando principalmente a tranquilidade. Por fim, a categoria "Sentimentos manifestados pelos pacientes durante o período perioperatório", detalha os principais sentimentos vivenciados pelos pacientes durante este período, e a que estão relacionados.

\section{Ações educativas desenvolvidas no período perioperatório na percepção dos pacientes}

A partir das questões levantadas sobre as ações educativas desenvolvidas no período perioperatório, $50 \%$ dos participantes afirmaram terem tido algum tipo de orientação quanto à 
internação e rotinas da unidade, os outros 50\% não identificaram o desenvolvimento das ações educativas, justificando que nenhum profissional teria realizado esta prática. Dos participantes que afirmaram terem recebido algum tipo de orientação, $12,5 \%$ declarou ter sido orientado por profissionais de enfermagem e medicina, já $87,5 \%$ dos participantes apenas por profissionais da medicina. É possível perceber que em geral os participantes apresentaram dificuldade para identificar alguma orientação realizada pelos profissionais de saúde.

Eu estava no corredor esperando uma consulta e o médico me viu e me chamou. Ficamos uma meia hora conversando e ele me explicou tudo. (P3) Não, acho que não. Só falaram para mim aguardar ser chamado(P4).

Me explicaram lá no Pronto Atendimento como era a internação, a médica e as enfermeiras me explicaram. ...Aqui ninguém me explicou nada. (P7)

Quando questionados se algum profissional havia realizado orientações referente ao procedimento cirúrgico a que seriam submetidos, e qual profissional a realizou, apresenta-se em destaque que $87,5 \%$ dos participantes mencionaram terem sido orientados apenas por profissionais da medicina, e $12,5 \%$ por profissionais da medicina e enfermagem. Ainda, evidenciam-se nas falas que as explicações (ações educativas) realizadas pelos médicos foram resultados de suas indagações. Durante a coleta dos dados, a partir de gestos e tonalidade da voz dos participantes, foi possível perceber a insatisfação quanto aos momentos e locais escolhidos para realização das ações educativas. Essas ações foram realizadas ou dentro da sala cirúrgica durante o preparo da anestesia ou após o procedimento cirúrgico quando o paciente já havia retornado ao leito da clínica cirúrgica.

O médico que fez a cirurgia me explicou quando eu estava recebendo a anestesia. Ele falou que seria o responsável pela cirurgia e que iria retirar parte do meu intestino.(P2)

Não, praticamente não. Eu conheci o médico depois da cirurgia. ...Ele só veio depois para explicar o que ele tinha feito, como tinha feito. (P4)

Por outro lado, um dos participantes demonstrou satisfação em relação à maneira e local onde foram realizadas estas ações. O mesmo estava realizando consultas periódicas antes da 
internação e já havia discutido com seu médico o procedimento que seria realizado e quais as possíveis consequências do mesmo.

Na consulta que eu vim fazer aqui para mostrar os exames, o médico já me explicou tudo da cirurgia. Como ela ia ser, disse que era longa, que eu poderia ficar com algumas sequelas. Isso bem antes da cirurgia. (P3)

Ao questionar os participantes sobre como foram e como gostariam de ser orientados, $62,5 \%$ trouxeram que as ações educativas realizadas não abordaram suas maiores preocupações. Pode-se observar, em suas manifestações, que as orientações se concentram em como será ou foi realizada a cirurgia, tendo como foco principal os aspectos bio-fisiológicos.

Fui orientado que podia ficar com sequelas, que iria ser uma cirurgia muito difícil e que teria de tirar uma costela. Exatamente como foi. $O$ médico falou explicou tudo o que eu queria saber. (P3)

Os médicos vieram falar comigo depois da cirurgia, de como ela tinha sido. [o que o paciente gostaria] Que falasse do tempo, de recuperação. Se iria poder voltar a trabalhar, se iria poder tirar a colostomia. Isso eu acho o mais importante para mim. O resto eu nem entendo muito. $(\mathrm{P} 4)$

Eu queria saber dos riscos de perder a perna, tava com muito medo disso, mas eles não falaram nem quando eu perguntei. (P5)

O médico falou que tinha que tirar coágulos. [o que o paciente gostaria] Eu queria saber quanto tempo vou ter que ficar de repouso, sem poder fazer nada.(P6)

É possível perceber que 37,5\% dos participantes demonstraram satisfação com as ações educativas realizadas. No entanto, uma das inquietações mais recorrentes nas falas dizem respeito à necessidade de alguns pacientes em receber informações acerca de sua recuperação pós procedimento cirúrgico e a possibilidade de retomar seu estilo de vida sem prejuízos permanentes.

Neste sentido, fica evidente a invisibilidade ou dificuldade de identificação dos profissionais de enfermagem dentro da equipe multiprofissional de saúde, o que nos faz refletir sobre como estamos desenvolvendo essas ações educativas e em que momento, para que os 
9 | Böck A, Nietsche EA, Terra MG, Cassenote LG, Wild CF, Salbego C

pacientes não lembrem ou não as percebam. Ainda, a fala dos participantes confirma o que a literatura traz sobre os benefícios relacionados às ações educativas em saúde no período perioperatório. No entanto, é necessário desenvolver estas ações a partir das necessidades expostas pelos pacientes.

\section{Contribuições das ações educativas no perioperatório}

Quando questionados se as ações educativas desenvolvidas teriam gerado alguma contribuição, os participantes da pesquisa relataram perceber um efeito positivo em relação às ações realizadas pelos profissionais. Percebe-se que uma das maiores contribuições das ações educativas foi a tranquilidade gerada após essas ações. Outras contribuições relatadas também foram à melhora do entendimento no momento vivenciado e o enfrentamento da situação cirúrgica e internação.

Não ficar tão nervosa, ficar mais tranquila, de saber o que iria ser feito e como poderia ficar. Aí a gente não fica imaginando tanta bobagem, de como pode ficar. Pensa direito no que foi falado. (P1)

Me ajudaram a enfrentar a situação e foi muito bom. Se tu chega cru, aí tu não vai conseguir enfrentar a situação. E sabendo o que você vai fazer, você já vem preparado. ...eu acho que funcionou muito bem. (P3)

Ajudaram a entender melhor como estão acontecendo as coisas. Ajuda um pouco a organizar a família também,...tem que saber as coisas daqui para poder organizar tudo. (P4)

Quando questionados se as ações educativas realizadas foram suficientes para esclarecer suas dúvidas, $87,5 \%$ dos participantes relataram terem sido suficientes. No entanto, é possível perceber a associação da ausência de dúvidas com a dificuldade de entendimento pelo uso de termos técnicos da área da saúde durante a comunicação entre profissionais e pacientes, sem a explicação do significado dos mesmos, o que demonstra que o processo de comunicação, por vezes não foi efetivo. 
Não, pelo fato de eu não entender muito bem os termos da área de saúde, os termos técnicos usados, muitas vezes me frearam no entendimento.... (P2)

...eles [médicos] tem uma maneira mais difícil de falar, e eu sou mais humilde. Mas eu sempre perguntei quando eu tinha dúvidas. (P8)

Em contraponto, um participante não relatou dúvidas devido às explicações e esclarecimentos realizados pelos profissionais de saúde serem satisfatórias ao seu ponto de vista.

Para mim foi bem explicado, com os pontinhos em seus lugares. Eu não tinha nenhuma dúvida. (P3)

Foi possível perceber que umas das maiores contribuições das ações educativas desenvolvidas no período perioperatório foi a tranquilidade, segurança, confiança e autonomia gerada após essas ações. Outras contribuições relatadas também foram o auxílio ao entendimento do momento vivenciado e enfrentamento da situação vivenciada de cirurgia e internação. No entanto, estas não foram suficientes para o entendimento de todos os pacientes. É necessário repensar a maneira que se fala e a linguagem que se utiliza nestas orientações.

\section{Sentimentos manifestados pelos pacientes durante o período perioperatório}

Quando questionados a respeito dos sentimentos vivenciados no período pré-operatório, os participantes da pesquisa perceberam sentimentos e sensações de medo, nervosismo, preocupação e tristeza. É possível perceber que a preocupação dos participantes está relacionada com a incerteza dos eventos e possíveis riscos pós-cirúrgicos, que vão desde o medo de perder um membro do seu corpo, a mudança do estilo de vida, a dor incessante, medo da solidão e morte.

Quando eu cheguei eu estava bem nervosa, bem assustada... tive um pouco de medo [de ficar sozinha, sem a minha família]. Tive vários momentos tristes. (P1)

Eu estava bem preocupado, confuso, porque não sabia muito bem o que eu tinha e o que iria acontecer comigo. (P2)

Eu não tinha escolha. ... se eu quisesse viver eu teria que fazer a cirurgia, $e$ eu queria viver. Eu estava com medo de morrer. (P6) 
11 | Böck A, Nietsche EA, Terra MG, Cassenote LG, Wild CF, Salbego C

No período pós-operatório os participantes relataram sentimentos e sensações de tranquilidade, alívio, desconforto e preocupação. A tranquilidade está diretamente ligada ao diálogo mantido com a equipe de multiprofissional de saúde. O desconforto está ligado a condição pós cirúrgica e a algumas restrições que essa implica, como a locomoção. Também, um dos participantes relata a consciência dos riscos que o meio hospitalar oferta ao referir preocupação com as infecções.

...agora estou bem mais calma, bem mais tranquila, até porque as enfermeiras vem tranquilizar a gente, estou bem mais calma. (P1)

Ah, um desconforto, por que delimita uma série de coisas.... (P2)

Aqui é muito bom, mas está cheio de bactérias por aí, a gente fica preocupado de pegar uma infecção. (P8)

A respeito dos sentimentos vivenciados em relação à hospitalização, os participantes relataram nervosismo, solidão, saudade e tristeza. É possível observar que os sentimentos de tristeza e saudade estão relacionados à falta que a presença da família faz neste processo de internação. Seja pela privação de tempo com a família em decorrência do horário de visitas, ou da impossibilidade das visitas familiares devido a distância dos municípios onde residem.

Triste de ficar sozinha ...Eu sentia muita falta da minha familia! Agora está melhorando. (P1)

Fiquei muito nervosa, fiquei por que... eu acho que é por causa da mudança de hábitos. Eu fui muito bem atendida, mas é diferente de casa. (P8)

Em contrapartida, um participante referiu estar se sentindo bem devido ao atendimento recebido por parte da equipe de saúde que, por vezes, promove descontração no ambiente hospitalar, por meio de conversas, brincadeiras e também música.

Estou sendo bem tratada em todos os sentidos. ... a gente é tratada com carinho, como gente, com brincadeiras, com sorrisos. Aí o tempo vai passando e a gente não tem tempo de pensar em tristeza, em coisas negativas. Aqui todo mundo [equipe de saúde] te cumprimenta, te olha no olho, e isso é muito importante. (P6) 
Ao questionar os participantes a respeito de seus sentimentos antes e depois das ações educativas, alguns referiram estarem ansiosos, frustrados, inseguros, com medo e nervosos antes das ações educativas. Após as ações educativas, os mesmos relataram maior tranquilidade e consciência do que aconteceria posteriormente, o que contribuiu para o enfrentamento do evento da internação.

Eu estava bem perdido! Estava muito nervoso, um pouco frustrado devido a não saber o que fazer na hora. Foi bem ruim essa não informação, antes de entrar no Bloco Cirúrgico! Depois [das ações educativas] me senti bem mais tranquilo pelo fato de ter esclarecido essas dúvidas mais pontuais. (P2)

Eu estava muito ansiosa antes. ...Fiquei muito melhor depois, por que a gente fica mais tranquila e consciente das coisas que podem acontecer. (P8)

Um dos participantes referiu que após as ações educativas seu medo em relação ao procedimento cirúrgico diminuiu consideravelmente. No entanto, o medo de ficar sem um acompanhante de sua família durante o procedimento operatório e durante o pós-operatório não diminuiu. Também, é possível perceber que outro atribui suas forças à fé para enfrentar sua hospitalização e o procedimento cirúrgico.

Antes eu estava com medo, por que eu não sabia o que eu tinha, o que os médicos iriam fazer. ...medo de ficar sozinha, por não ter alguém da minha familia por perto, uma insegurança. Aí depois que eles explicaram aliviou o medo da cirurgia, mas de ficar sozinha não!. (P1)

Eu estava tranquilo, estava nas mãos de Deus! Eu sou salvo, então sempre fiquei tranquilo. Sabia que o que a medicina podia fazer ela ia fazer, então nunca me abalei!. (P4)

Os sentimentos percebidos pelos pacientes durante o período perioperatório foram de medo, nervosismo, preocupação e tristeza no pré-operatório. Preocupação relacionada com a incerteza dos eventos que iriam acontecer, com a possibilidade de amputação de um membro e com a possibilidade de não mais poder falar e suas repercussões na rotina de vida. O medo 
referido por alguns participantes estava relacionado ao fato de ficar sozinho, sem a companhia da família, de não conseguir diminuir ou cessar a dor e também o medo da morte. No período pós-operatório, os participantes relataram sentimentos e sensações de tranquilidade, preocupação, conforto, desconforto e alívio.

\section{Discussão}

A hospitalização é um acontecimento indesejado e traz consigo características estressantes. Os pacientes se deparam com inúmeras informações novas relacionadas ao procedimento cirúrgico e a internação. Nesse contexto, a responsabilidade de cuidar da vida, que antes era do próprio paciente, acaba sendo compartilhada com familiares e profissionais de saúde. ${ }^{5-6}$

Em meio a esse contexto os pacientes vivenciam mudanças de rotina. Para o seu auxílio, é preciso que a equipe multiprofissional desenvolva as ações de saúde de maneira articulada, utilize a mesma linguagem e reforce as orientações necessária. ${ }^{7-8}$

Durante as observações realizadas na clínica cirúrgica, foi possível perceber que as orientações quanto ao funcionamento da unidade e suas rotinas são dadas no momento da internação pela equipe de enfermagem. No entanto, nesta pesquisa, apenas um dos participantes recordou o momento em que o responsável de enfermagem juntamente com um profissional da medicina realizou a orientação na unidade. Os demais, recordaram somente das orientações médicas fornecidas. Diante disso, as ações educativas quanto à internação e ao procedimento cirúrgico devem ser realizadas de forma clara e sucinta, buscando esclarecer as dúvidas e informando sobre os principais procedimentos que serão realizados.

Evidencia-se como possíveis fragilidades nas orientações, a falta de informações quanto ao tempo de recuperação e o processo de reabilitação após a alta hospitalar, pois é comum nesse período o surgimento de dúvidas quanto a mudança de rotinas e hábitos decorrentes da cirurgia. 
Essa carência de informações, muitas vezes, se deve ao fato de não haver uma padronização das orientações e rotinas cirúrgicas. Os pacientes podem vir a manifestar o sentimento de impotência em recuperar sua autonomia, pois durante a permanência no hospital até o período que precede a alta, o paciente necessita de cuidados de terceiros.

Cabe destacar, que o paciente deve ser orientado no momento em que o procedimento cirúrgico é marcado, pois quanto mais próximo é o procedimento maior é a dificuldade de assimilar as informações devido ao nervosismo, potencializando assim a ansiedade. ${ }^{7}$ Para tanto, é necessário o acompanhamento dos pacientes cirúrgicos e as ações educativas no período préoperatório pela equipe de saúde. ${ }^{9}$

Estas ações educativas contribuem para deixar o paciente mais próximo do que será realizado no momento cirúrgico, e assim reduzem os níveis de ansiedade. Auxiliam no esclarecimento quanto às dúvidas que a intervenção cirúrgica provoca, como a duração da internação hospitalar, tempo de reabilitação, e podem minimizam as complicações pósoperatórias por meio do esclarecimento acerca dos cuidados a serem tomados.

Para que esse processo seja efetivo, é importante que o profissional de saúde realize as ações educativas direcionadas ao paciente, de forma clara e tendo o cuidado questionar e de responder às perguntas de acordo com o nível de informação e de entendimento do paciente, além de serem realizadas em lugar adequado que propicie privacidade. ${ }^{10}$ Durante as observações, foi possível observar que as ações educativas são realizadas à beira do leito no momento da visita ou de algum procedimento.

É preciso escutar/identificar quais informações o paciente necessita, com vistas a desenvolver uma orientação de maneira efetiva que minimize dúvidas, medos, anseios, angústias, entre outros. Muitas vezes, suas dúvidas não estão concentradas nas questões fisiológicas e técnicas do procedimento cirúrgico, e sim no tempo de recuperação e se há a possibilidade de retomar a rotina mantida anteriormente. As informações quanto a recuperação, 
15 | Böck A, Nietsche EA, Terra MG, Cassenote LG, Wild CF, Salbego C

muitas vezes, estão relacionadas a (re)estruturação familiar e orçamentária, sendo que o evento da internação e procedimento cirúrgico nem sempre são programados pelo paciente e sua família.

Dentro da equipe de saúde, cada profissional possui sua rotina. Os profissionais de enfermagem efetuam essas ações a beira do leito e, esporadicamente, em plantões com menor demanda de atividades assistências, convida os pacientes para se deslocarem até uma sala reservada, onde contam também com materiais ilustrativos (bonecos com drenos e curativos, imagens anatômicas, manuais, dentre outros) que auxiliam no desenvolvimento dessas ações. Os demais profissionais de saúde como fisioterapeutas, nutricionistas e psicólogos realizam orientações pontuais e necessárias para o momento presente vivenciado do paciente. Ainda, profissionais de saúde como odontólogos são solicitados para orientações conforme avaliação dos profissionais de enfermagem.

As orientações pré-operatórias e o apoio psicológico são vistos como benéficos, se baseados nas necessidades individuais do paciente pois, na medida em que suas dúvidas são esclarecidas, diminuem seus medos. ${ }^{11}$ Para isso, os profissionais de saúde devem estar preparados e fornecer as informações forma humanística e holística, auxiliando o paciente a encontrar mecanismos de enfrentamento eficazes para o momento vivenciado, entendendo melhor sua situação, e essa compreensão contribui para amenizar sua ansiedade. ${ }^{11-15}$

Nesse contexto de espera e ansiedade que envolve o processo cirúrgico, os familiares também estão intimamente envolvidos e compartilham com o paciente seus sentimentos e incertezas, tornando o manejo dessa situação ainda mais complexa para a equipe de saúde, visto que esses momentos são presenciados de perto por ela, pois está presente desde os cuidados pré-operatórios. A equipe multiprofissional necessita estar ciente do quadro clínico do paciente, mas também precisam saber ouvir, apoiar e auxiliar o paciente a compreender e enfrentar a situação vivenciada. ${ }^{14-16}$ 
Não menos importante, o pós-operatório exige da equipe de saúde uma vigilância contínua, a fim de detectar qualquer alteração nas condições gerais do paciente. É necessário que o profissional de saúde converse com o paciente no pós-operatório, bem como esteja sempre ao seu lado, orientando-o e tranquilizando-o quanto aos seus sentimentos e emoções, bem como dar apoio a seus familiares. Nesse contexto, a família é considerada essencial para a recuperação do paciente, porque ajuda no restabelecimento do equilíbrio psicológico e diminuição de sofrimento, além de proporcionar coragem e esperança para que a recuperação seja muito mais rápida. ${ }^{17}$

O trabalho em saúde sob uma perspectiva que envolva a religiosidade e espiritualidade contribui para a sensação de bem-estar, reduz os níveis de angústia e impotência. Nesse contexto, a religião, por vezes, adota um lugar de refúgio para a desordem instalada pela doença, e conforto para os medos e inseguranças desencadeados pela sensação de morte. Por meio da religião, os pacientes conferem sentido à situação de adoecimento, possibilitando uma explicação para a impossibilidade de controlar a situação ${ }^{18}$.

Diante disso, o bem-estar do paciente deve constituir o principal objetivo dos profissionais que o assistem, pois no período perioperatório estes podem apresentar um alto nível de estresse, ansiedade e desconfortos, bem como desenvolver sentimentos que podem atuar negativamente em seu estado emocional, tornando-os vulneráveis e dependentes. Sendo assim, são importante as ações educativas para amenizar o medo e ansiedade, auxiliando os pacientes e acompanhantes a enfrentar o ato cirúrgico mais fortalecidos emocionalmente.

\section{Conclusão}

Evidencia-se, neste estudo, as inúmeras contribuições das ações educativas para os pacientes cirúrgicos no período perioperatório. Também sugere-se uma profunda reflexão sobre como os profissionais de saúde estão desenvolvendo as ações educativas, a qualidade da 
17 | Böck A, Nietsche EA, Terra MG, Cassenote LG, Wild CF, Salbego C

comunicação/apresentação pessoal, período investido para estas ações e o momento em que estão sendo realizadas.

A equipe de saúde necessita realizar ações educativas com o paciente durante todo o período perioperatório visando ao preparo físico, psicológico e espiritual. Para que estas orientações realmente possam satisfazer as necessidades dos pacientes, os profissionais necessitam atentar para a linguagem utilizada durante as ações educativas, termos científicos devem ser evitados para a melhor compreensão das orientações realizadas. As discordâncias de orientações entre os profissionais precisam ser evitadas, estas informações carecem ser planejadas pelos profissionais de saúde e reforçadas constantemente.

Nesse sentido, a intersetorialidade e as redes de atenção à saúde podem auxiliar na reestruturação das ações educacionais. Ainda, propiciam a continuidade e a integralidade do cuidado aos pacientes cirúrgicos, favorecendo o melhor entendimento do momento vivenciado. Enfim, pretende-se com este estudo, instigar reflexões sobre a maneira como nos comunicamos com os pacientes, repensar nossa linguagem e abordagem, além de instigar a reflexão sobre o papel do profissional de saúde relacionado às ações educativas.

Considerou-se limitação deste estudo o número de participantes da pesquisa, o que pode não ter evidenciado em sua totalidade a percepção dos pacientes cirúrgicos acerca das ações educativas desenvolvidas no período perioperatório. Ainda, o estudo também foi realizado em um único hospital, sendo necessárias outras pesquisas em hospitais para confirmar os resultados encontrados, possibilitando comparações e possíveis generalizações.

\section{Referências}

1. Ascari RA, Neiss M, Sartori AA, Silva OM, Ascari TM, Galli KSB. Perceptions of surgical patient during preoperative period concerning nursing care. Rev Enferm UFPE [Internet]. 2013 [acesso em 2017 set 17];7(4):1136-44. Disponível em:

https://periodicos.ufpe.br/revistas/revistaenfermagem/article/view/11590 
2. Lima AB, Barbosa PMK, Morita I. Patients with total primary hip arthroplasty: feelings experienced. Rev Min Enferm [Internet]. 2014 [acesso em 2017 set 14];18(4):789-94. Disponível em:

https://www.researchgate.net/publication/276906036_Patients_with_primary_total_hip_arthropl asty_feelings_experienced doi: 10.5935/1415-2762.20140058

3. Knihs NS, Valmorbida AP, Lanzoni GMM, Roza BA, Ghellere A. Caminho percorrido até a cirurgia cardíaca: necessidades e expectativas no pré-operatório. Av Enferm [Internet]. 2017 [acesso em 2017 ago 24];35(1):30-41. Disponível em:

http://www.scielo.org.co/scielo.php?pid=S0121-45002017000100004\&script=sci_abstract\&tlng=pt

4. Bardin L. Análise de conteúdo. São Paulo: Edições 70; 2011.

5. Pérez Júnior EF, Pires AS, Jomar RT, Peres EM, Gomes AMT, Rocha AC. Sistematização da assistência de enfermagem aplicada a um adolescente hospitalizado por paracoccidioidomicose. Rev Enferm UERJ [Internet]. 2015 [acesso em 2017 set 17]; 23(6):767-2. Disponível em: http://www.e-publicacoes.uerj.br/index.php/enfermagemuerj/article/view/18764

6. Gonçalves KKN, da Silva JI, Gomes ET, Pinheiro LLS, Figueiredo TR, Bezerra SMMS. Anxiety and depression in the preoperative period of cardiac surgery. Rev Bras Enferm [Internet]. 2016 [acesso em 2017 out 14];69(2):397-403. Disponível em: http://www.scielo.br/pdf/reben/v69n2/en_0034-7167-reben-69-02-0397.pdf

7. Rosseto KRC, Nunes KZ, Romero WG, Furieri LB, Massaroni L, Fioresi M. Intervenção educativa de enfermagem ao cliente submetido à cirurgia cardíaca. Rev Baiana Enferm [Internet]. 2017 [acesso em 2017 set 23];31(4):e22441. Disponível em: https://portalseer.ufba.br/index.php/enfermagem/article/view/22441/15609

8. Oliveira KRE, Braga EM. The development of communication skills and the teacher's performance in the nursing student's perspective. Rev Esc Enferm USP [Internet]. 2016 [acesso em 2018 jan 13];50(spec):32-8. Disponível em: http://www.scielo.br/pdf/reeusp/v50nspe/0080-6234reeusp-50-esp-0032.pdf

9. Costa TMN, Sampaio CEP. As orientações de enfermagem e sua influência nos níveis de ansiedade dos pacientes cirúrgicos hospitalares. Rev Enferm UERJ [Internet]. 2015 [acesso em 2018 jan 13];23(2):260-5. Disponível em: http://www.epublicacoes.uerj.br/index.php/enfermagemuerj/article/view/16534/12811

10. Barbosa AC, Terra FS, Carvalho JBV. Humanização da assistência médica e de enfermagem ao paciente no perioperatório em um hospital universitário. Rev Enferm UERJ [Internet]. 2014 
19 | Böck A, Nietsche EA, Terra MG, Cassenote LG, Wild CF, Salbego C

[acesso em 2018 jan 20];22(5):699-704. Disponível em: http://www.epublicacoes.uerj.br/index.php/enfermagemuerj/article/view/16460

11. Beserra EP, Oliveira FC, Ramos IC, Moreira RVO, Alves MDS, Braga VAB.

Human suffering and nursing care: multiple visions. Esc Anna Nery Rev Enferm [Internet]. 2014 [acesso em 2018 jan 23];18(1):175-80. Disponível em: http://www.scielo.br/scielo.php?pid=S1414$81452014000100175 \&$ script $=$ sci_arttext\&tlng=en

12. Morales CLP, Alexandre JG, Prim S, Amante LN. Perioperative communication from the perspective of patients undergoing bariatric surgery. Texto \& Contexto Enferm [Internet]. 2014 [acesso em 2018 jan 24];23(2):347-55. Disponível em:

http://www.scielo.br/scielo.php?script=sci_arttext\&pid=S010407072014000200347\&lng=en\&n rm=i so\&tlng=pt

13. Santos MMB, Martins JCA, Oliveira LMN. A ansiedade, depressão e stresse no préoperatório do doente cirúrgico. Rev Enf Ref [Internet]. 2014 [acesso em 2018 jan 13];serIV(3):7-15. Disponível em: http://www.scielo.mec.pt/scielo.php?script=sci_arttext\&pid=S087402832014000300002

14. Mendonça ET, Lopes JM, Ribeiro L, Sá FBB, Oliveira DM, Salgado PO. Concepções de técnicos de enfermagem acerca da humanização da assistência em centro cirúrgico. Rev Enferm Cent-Oeste Min [Internet]. 2016 [acesso em 2018 jan 24];6(3):2389-7. Disponível em:

http://www.seer.ufsj.edu.br/index.php/recom/article/view/1177

15. Kalogianni A, Almpani P, Vastardis L, Baltopoulos G, Charitos C, Brokalaki H. Can nurseled preoperative education reduce anxiety and postoperative complications of patients undergoing cardiac surgery? Eur J Cardiovasc Nurs [Internet]. 2015 [acesso em 2018 nov 30]; 14(4):1-12.Disponível em: https://www.ncbi.nlm.nih.gov/pubmed/26304701

16. Lima WG, Nunes SFL, Alvarez AM, Valcarenghi RV, Bezerra MLR.

Principais diagnósticos de enfermagem em idosos hospitalizados submetidos às cirurgias urológicas. Rev Rene [Internet]. 2015 [acesso em 2018 jan 24];16(1):72-80. Disponível em: http://repositorio.ufc.br/bitstream/riufc/11299/1/2015_art_wglima.pdf

17. Rosseto KRC, Nunes KZ, Massaroni L, Fioresi M. O processo educativo do enfermeiro sob a ótica de clientes submetidos à cirurgia cardíaca. Rev Bras Pesq Saúde [Internet]. 2016 [acesso em 2017 set 23];18(4):22-9. Disponível em: http://periodicos.ufes.br/RBPS/article/view/16726/11557

18. Sowa A, Golinowska S, Deeg D, Principi A, Casanova G, Schulmann K, et al. Predictors of religious participation of older Europeans in good and poor health. Eur J Ageing [Internet]. 2016 
Ações educativas desenvolvidas no período perioperatório em um hospital universitário... | 20

[acesso em 2018 nov 30];13(2):145-7. Disponível em:

https://www.ncbi.nlm.nih.gov/pmc/articles/PMC4902827/

\section{Autor correspondente}

Andressa Böck

E-mail: bockandressa@gmail.com

Endereço: Praça Oswaldo Aranha, no 85, Centro, Alegrete, Rio Grande do Sul, Brasil.

CEP: $97541-540$

\section{Contribuições de Autoria}

1 - Andressa Böck

Concepção e planejamento do projeto de pesquisa, obtenção ou análise e interpretação dos dados, redação e revisão crítica.

2 - Elisabeta Albertina Nietsche

Concepção e planejamento do projeto de pesquisa, obtenção ou análise e interpretação dos dados, redação e revisão crítica.

3 - Marlene Gomes Terra

Concepção e planejamento do projeto de pesquisa, obtenção ou análise e interpretação dos dados.

4 - Liege Gonçalves Cassenote

Concepção e planejamento do projeto de pesquisa, obtenção ou análise e interpretação dos dados.

5 - Camila Fernandes Wild

Concepção e planejamento do projeto de pesquisa, obtenção ou análise e interpretação dos dados.

6 - Cléton Salbego

Redação e revisão crítica.

\section{Como citar este artigo}

Böck A, Nietsche EA, Terra MG, Cassenote LG, Wild CF, Salbego C. Ações educativas desenvolvidas no período perioperatório em um hospital universitário: percepção de pacientes cirúrgicos. Rev. Enferm. UFSM. 2019 [Acesso em: Anos Mês Dia];vol e28: P1-P20. DOI:https://doi.org/10.5902/2179769234760 